\title{
Selected faults of low-speed machines, analysis of diagnostic signals
}

\author{
Emil Golonka ${ }^{1, *}$ and Michat Pająk ${ }^{1}$ \\ ${ }^{1}$ University of Technology and Humanities in Radom, Faculty of Mechanical Engineering, \\ Stasieckiego Street 54, 26-600 Radom, Poland
}

\begin{abstract}
In an industrial environment, a large part of the solutions used in machine parks is based on rotating systems. Therefore, the branches of diagnostics in this area are subjected to extensive research so that they effect with more and more new solutions. This article presents the problem of selected most common faults in a low-speed machinery environment. Presented chapters define the concept of symptoms and diagnostics and define its goals. Selected issues of the analysis of diagnostic signals were also discussed.
\end{abstract}

\section{Low speed rotating machinery}

Slow-speed rotating machines are the basis of operating in many production branches all around the world. The one, specific definition of the speed at which low-speed machines rotate does not exist. However, the speed of $600 \mathrm{rpm}$ is generally considered to be the minimum for the machines rotating at medium speed. For this reason, machines with a rotational speed of less than $600 \mathrm{rpm}$ are commonly classified as slow-running machines [1]. Also, there are studies and articles available according to which low-speed machines are those whose rotational speed does not exceed several dozen revolutions per minute [2]. These machines tend to be large and are critical components in production lines. An example of the use of low-speed machines are small hydropower plants. Due to the low failure rate of the elements of the above-mentioned machines, monitoring the condition of this type of machines was not a priority for many years. However, in the event of a breakdown, the costs caused by line downtime or the mere replacement of an element bring huge losses.

It should be noted that the diagnostics of slow-rotating machines is a demanding process. Defects can develop very slowly until they are revealed (to a noticeable failure) then it is only possible to apply corrective measures not preventive ones [3]. Moving elements of these machines, such as bearings, gears, rotors, gears of shafts, which are subjected to degradation over time, require sustained monitoring. At the same time, they are exposed to a certain range of repeatable errors and faults, thanks to which we are able to focus on the signals and monitor machines for the exclusion of known faults. The most common ones are presented in the following chapter.

\footnotetext{
* Corresponding author: emilgolonka@,op.pl
} 


\section{Diagnostic, signals and symptoms}

Diagnostic research is aimed at determining the state of a technical object, the process at the moment considered important for a particular research. Determining this state is essential to compare the actual state with the reference state and decide on the suitability or unfitness of a given technical object or process course. On the basis of such a comparison, forecasts of future states of technical facilities are also made [4, 5].

The aim of technical diagnostics is to determine the condition of a technical object by means of direct tests of their properties as well as indirect examination of the accompanying processes, the so-called residual processes. With each useful process performed by a technical object, there is also a generation of residual processes, e.g. thermal, vibroacoustics, thermal, etc. The impact of the machine on the environment is shown in Figure 1.

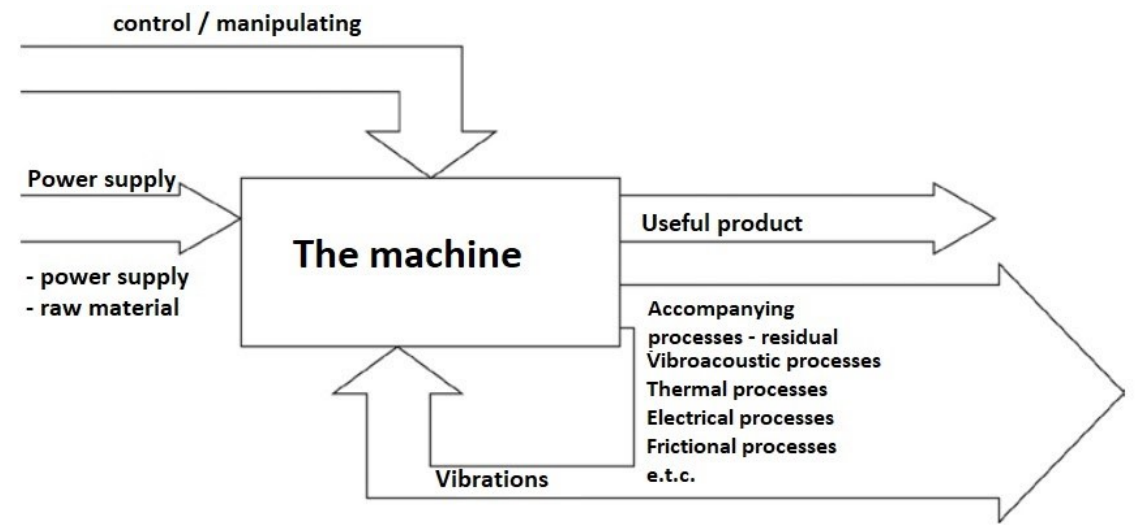

Fig. 1 Influence of the machines on the environment [6].

The purpose of machine diagnostics can be characterized as follows:

- diagnosis - determining the current technical condition,

- genesis - determining the causes of the current state,

- forecast - determining the time of a future change in the technical condition [7].

Features of the diagnostic signals of a device with a specific technical condition are symptoms of this condition. The symptoms of the state cannot be identified with the technical condition of the machine, because the symptoms are correlated with the state of the object. An objective assessment of the machine condition can be done by diagnostic inference of the observed symptoms [6, 8]. A state symptom has three sets of characteristics and parameters that can be observed. The first is the machine's working and functional parameters, such as speed, power, etc. The second are the parameters and characteristics that are a direct symptom of wear, such as deviations in shape and dimensions in relation to the pattern, clearances. The third is the research on residual processes, e.g. noise, vibrations, etc. It is necessary to verify the possible methods of damage in the facility and indicate the symptoms accompanying their operation, which will react from the beginning of the appearance of the defect in the shortest possible time [8]. 


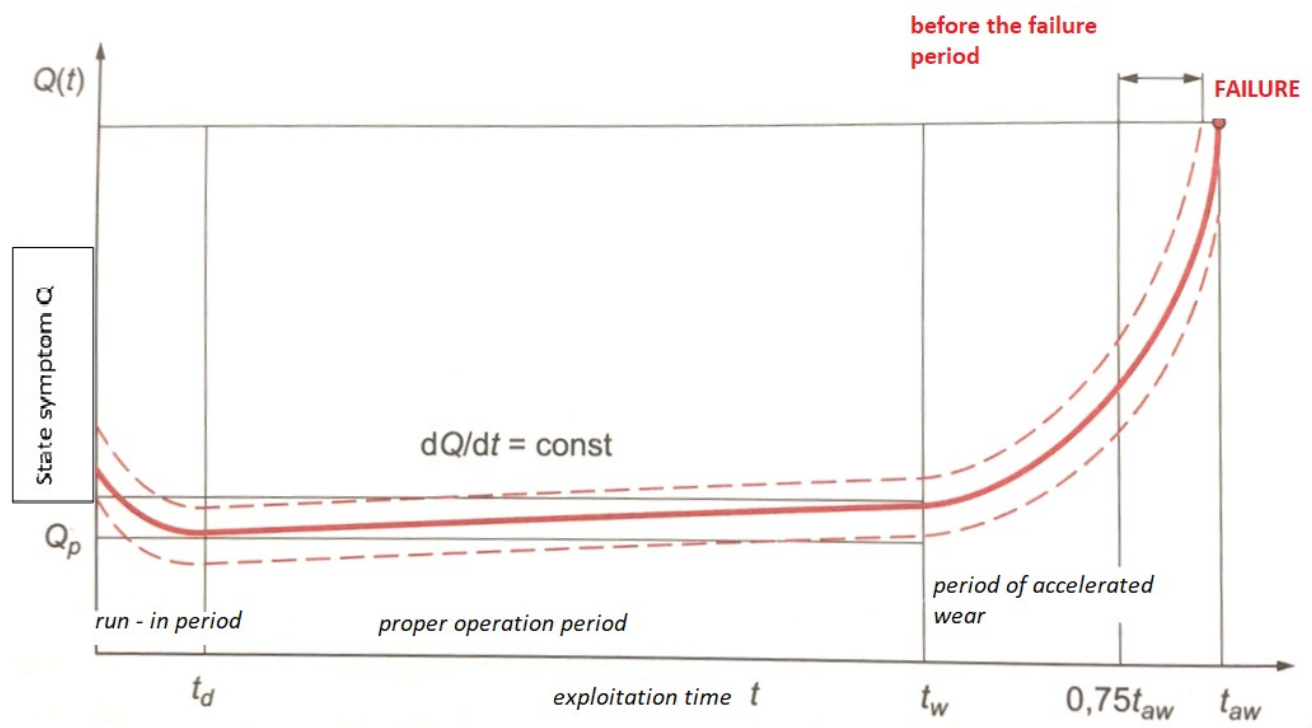

Fig. 2 The life curve of the machine [8].

Figure 2 shows the idea of machine operational diagnostics along with the machine wear curve. The use of technical diagnostics methods at each stage of the machine operation and analysis of the generated signals determines their condition. This allows you to anticipate the necessary inspections and repairs. Such information is very important, especially in strategic branches of the economy, such as power engineering, where shutting down a technical facility from operation carries large consequences and costs.

Technical diagnostics of machines can be broadly divided into two classes: symptomatic diagnostics and model-supported diagnostics. Symptomatic diagnosis is based mainly on an active and passive diagnostic experiment. The essence of model-supported diagnostics is to compare the results of observation of a working device with the results of its operation simulated by a model $[4,9]$.

\section{The most common faults}

Since the problem of damage to rotating devices is a very large area of research, the scope of this work must be limited. The most common flaws were selected on the basis of a literature analysis of the issue. The most common fault is unbalance, partly because of the fine tolerances used in the machines, but also because of the relationship between defects and unbalance. Misalignment can also be identified as another common malfunction. The defects will also be characterized: a bent shaft and damage to the bearings. Note that defects are not mutually exclusive, even though they have been classified into several categories. There are visible dependencies between some of the errors [10].

\subsection{Unbalance}

Unbalance is one of the most common defects in rotating objects. Every rotating object has an inherent degree of unbalance. Thus, an unbalance beyond a certain tolerance level can be defined as a fault [10]. It is the centrifugal force of an unbalanced mass in the rotating assembly that causes the object to vibrate. This happens when the centre of gravity of the 
rotating rotor is not on the axis of rotation [11]. "Rotor unbalance is a condition in which the mass distribution around the spin axis is such that during spinning the resultant centrifugal force causes a variable load on the rotor supports and its bending. The amplitude of machine vibrations is directly proportional to the amount of unbalance" [8]. Unbalance gives symptoms of intense vibrations of bearings, rotor, frame and foundations. This can lead to the destruction of bearings and entire machines.

Numerous experiments and theoretical considerations show that the increase in engine vibration velocity is due to unbalance. This can be observed in particular by measuring vibrations on bearings in the horizontal direction, i.e. the direction with the lowest stiffness. The vibration intensity of the object is approximately proportional to the square of the rotational speed; outside the resonance areas, it is not directly dependent on the load change[8, 12]. "The spectrum of the vibration velocity is polyharmonic with an unequivocal dominance of the component corresponding to the rotational speed. For example, for a squirrel-cage induction motor these are the vibrations with the rotation frequency" [8]:

$$
f_{r}=\frac{\mathrm{n}}{60}=\frac{f_{l}}{p} \cdot(1-s)
$$

where: $\mathrm{n}$ - rotor speed, $\mathrm{s}$ - slip, $\mathrm{p}$ - number of pole pairs, $\mathrm{f}_{\mathrm{l}}$ - supply network frequency.

Balancing is the process of correcting the weight distribution of, for example, an impeller or shaft. This process is carried out by adding or subtracting such a correction mass on the correction radius so that the sum of the centrifugal forces (sum of unbalances) is equal to zero. A necessary condition for the operation of any machine is its correct setting and balance. Symmetrically distributed masses in relation to the axis of rotation of the device balance the centrifugal forces, i.e. balance the object. Then the device works with little vibration and calmly $[8,12]$.

The most common causes of unbalance are: design errors, material defects, assembly errors, loosening and displacement of rotor elements, corrosion, thermal deformation, erosion and deposits on the rotor, cavitation, hydroaerodynamic factors, rotor abrasion, and creep.

\subsection{Misalignment}

Misalignment can be identified as another common fault that can result in significant damage to rotating equipment. Defect relationships are often closely related. In many cases, the misalignment itself may not be the cause of the failure, but may lead to, for example, abrasion of the casing [10]. Incorrect alignment of the shafts leads to: damage to the shaft itself and the clutch, damage to the bearings and seals, excessive loss of lubricant (through seals), an increase in vibration and noise, an increase in friction - an increase in energy consumption, damage to foundation bolts.

Misalignment occurs when the propeller shaft is misaligned in terms of the load or when the component connecting the engine to the load is misaligned. The following types of misalignment can be distinguished:

- angular misalignment: shaft centrelines are not parallel but intersect,

- Parallel misalignment: shaft centrelines are not concentric but parallel,

- Complex misalignment: this is a combination of angular and parallel misalignment $[10,13]$. 


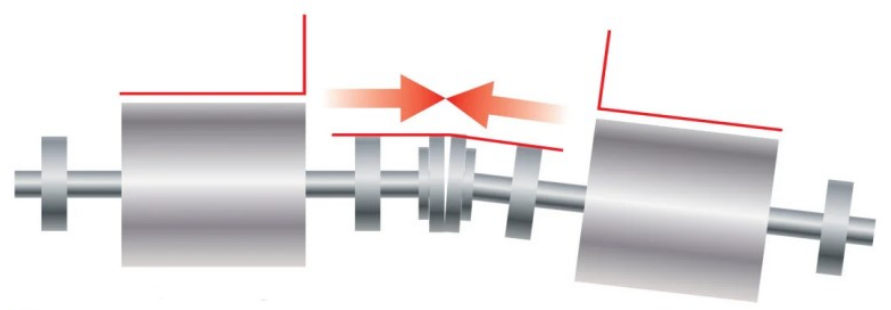

A.

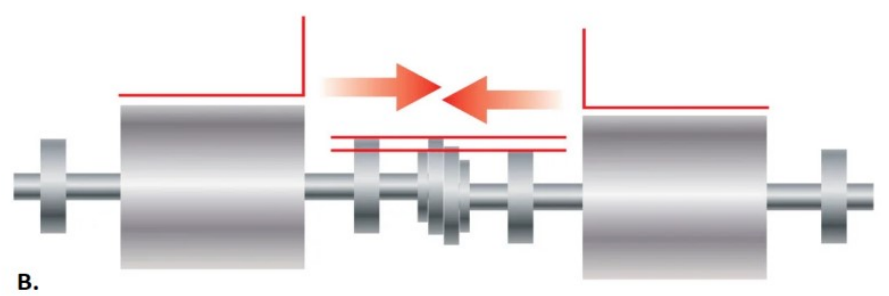

Fig. $3 \mathrm{~A}$ - angular misalignment, B - parallel misalignment [13].

\subsection{Bearings failure}

Bearing failure is a very common cause of failure of rotating machinery. In all power generators, the bearing is one of the key components. In addition to electric motors, bearings are also found in shaft supports, gears, clutches and electric motors. Thus, bearings are a common element of mechanical engineering and the share of bearings in the final cost of the device is usually small. However, in terms of the functions they perform and taking into account the statistics of their damage, it should be noted how important an issue in operational practice is the diagnostics of these elements $[8,10]$.

In electric motors, mainly rolling bearings are used. Their use determines the maximum load and limit rotational speeds. Plain bearings are used for engines with higher powers. The literature analysis of the operation of engines with plain and rolling bearings shows that engine failures caused by damage to the plain bearings are rare. Plain bearing failure tends to be slow, unlike rolling element bearings, which fails rapidly.

Two natural wear processes occur in rolling bearings: abrasive wear on the working surfaces and fatigue wear. The abrasion of the surfaces of the rolling parts increases with their service life. Rolling over the rolling parts of the bearing causes quality changes in the material. At the end of the bearing's service life, fragments of the bearing material begin to crumble and this phenomenon is called fatigue wear, and it proceeds like an avalanche. A damaged bearing results in an increase in the level of vibrations and noise, as well as an increase in friction - this is accompanied by an increase in the temperature of the bearing arrangement and lubricant leakage $[8,14]$.

By systematizing the types of damage most often given in the literature, we can list: flaking, sticking, cracks and chipping, damage due to the flow of electric current, seizure and corrosion. Another classification of the types of wear of rolling bearings has been introduced by the International Standard ISO 15243 Rolling bearings - Damage and failures - Terms, characteristics and causes. This division is shown in the figure below. 


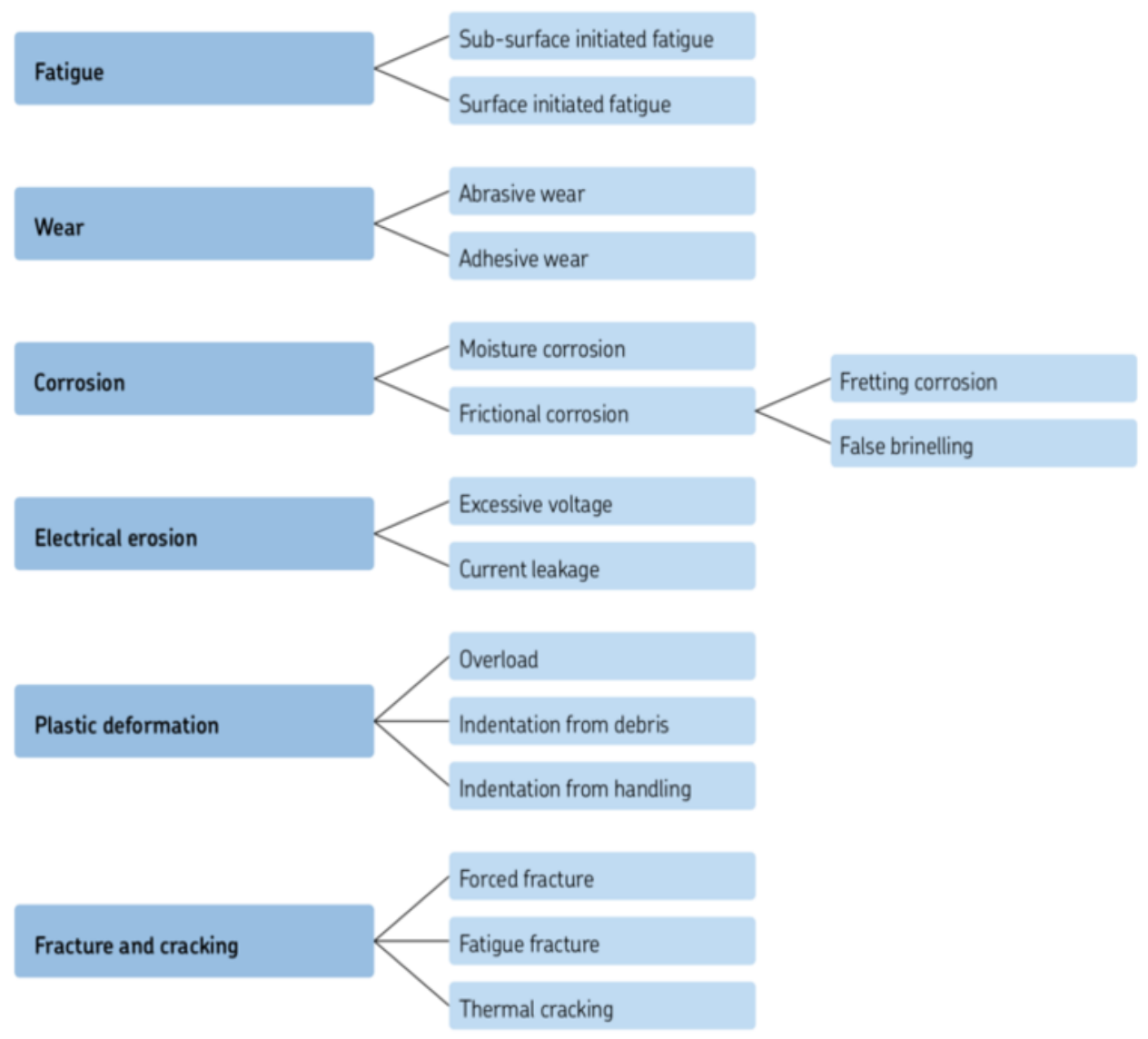

Fig. 4 Breakdown of damage to rolling bearings according to ISO 15243 [15].

\subsection{Bent shaft}

In the operation of power equipment, it is also encountered with a bent rotor shaft. This defect gives similar symptoms in the drag signal as in the case of a device with an unbalance. Determining the case of a bent shaft consists in measuring the vibrations on the bearings in the axial direction and verifying whether the phase angle of the rotational component measured in relation to the mark on the shaft shows a 180 degree difference in phase. Then, measurement of the bearings in the radial direction and verification whether the phase angle of the rotational component measured in relation to the mark on the shaft shows 0 degrees of difference in phase. The method of carrying out the measurement is shown in the figure below. Both conditions regarding the phase angle must be met [8]. 


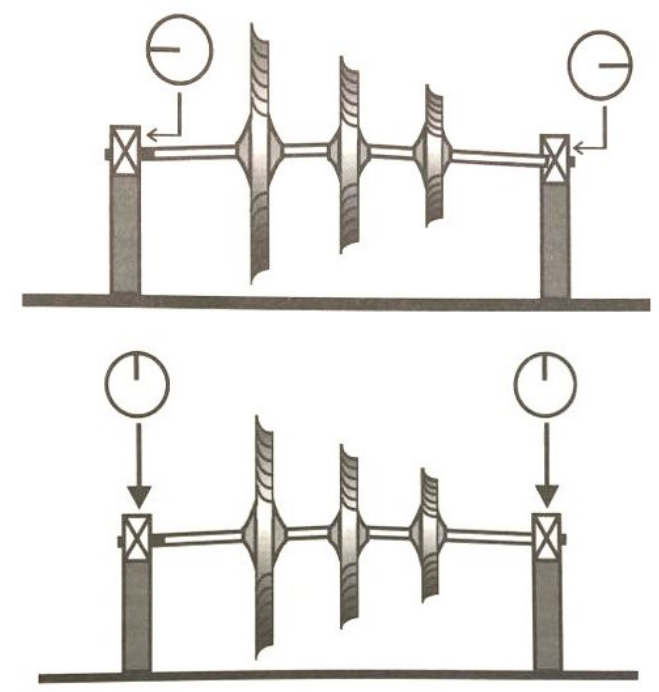

Fig. 5 Recognition of a bent shaft - measurement method [8].

\section{Analysis of diagnostic signals - selected issues}

Before starting the diagnostic measurements, it is necessary to carefully analyse the mechanism of the selected failure, which results in the failure. It is necessary to define the symptoms accompanying the occurrence of a given fault during the operation of the device, which indicate the possibility of a fault occurring in the near future.

A signal is a course of any physical quantity that can carry information. A diagnostic signal is signal carrying information about the state of an object. Models of physical signals can be divided into determined and indeterminate signals, i.e. random signals. The analysis of the determined signals can be performed with strict mathematical relationships. On the other hand, the analysis of undetermined signals can only be carried out with the help of certain averaged static characteristics, because they occur randomly and therefore cannot be described with strict mathematical relationships [8, 16]. Figure 6 shows a general classification of signals.

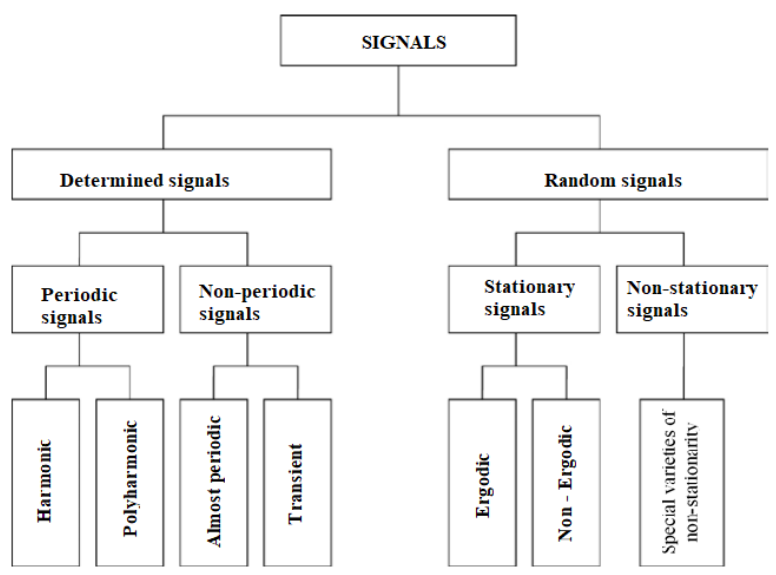

Fig. 6 General classification of signals [8]. 
"In practice, the basic analysis of the diagnostic signal is performed in the time domain the signal waveform, the graph of the function in time, and in the frequency domain - the signal spectrum, the graph of the effective values for individual signal components as a function of frequency" [8]. The analysis of dynamic processes of machines (acoustic and material vibrations) shows that they are created together by undetermined processes and determined processes. Determined signals appear in the form of physical phenomena that describe various mechanisms, e.g. vibrations of an unbalanced rotor, etc. In technical practice, there are many physical phenomena that can be described with high accuracy by exact mathematical relationships $[8,16]$. Harmonic signals belong to the group of periodic signals. They occur, for example, with vibrations of an unbalanced rotor or vibrations in voltage. In signal analysis, harmonics are one of the simplest functions of time and can be described by the function:

$$
x(t)=A \cdot \cos \left(2 \cdot \pi \cdot f_{0} \cdot t+\phi\right)
$$

where: A - signal amplitude (e.g. in $\mathrm{mm}$ ), $\mathrm{f}_{\mathrm{o}}$ - frequency (in $\mathrm{Hz}$, i.e. the number of cycles per second), $2 \cdot \pi \cdot f_{o}=\omega o$ - angular frequency (in $\mathrm{rad} / \mathrm{s}$ ), $\phi$ - phase shift ( $\left.\mathrm{rad}\right), \mathrm{t}$ - considered moment of time (s).

Polyharmonic signals can be described as a function of time by means of a linear combination of harmonics. The number of these components may in general be infinite. For a signal to be considered polyharmonic, the frequency of each of its components must be an integer multiple of a certain frequency called the fundamental frequency. Physical phenomena described by these signals appear much more often than phenomena expressed by harmonic functions. Almost periodic signals are created by summing several (many) harmonics with frequencies where at least one quotient is irrational. The base period of this signal is infinity. Transient (transient) signals are all non-periodic signals that are not nearly periodic signals. Transient signals cannot be represented by a discrete spectrum. Examples include an impulse, a rectangular input, or an exponential process. Random signals describe physical phenomena that cannot be described with unambiguous mathematical relationships due to the fact that each observation gives only one of many possible results. Single time functions describing a random phenomenon are called random realizations or functions. Execution in a finite period of time is an observed signal. The set of all random functions that constitute the implementation of a given random phenomenon is called a stochastic process or a random process $[8,16]$.

1)

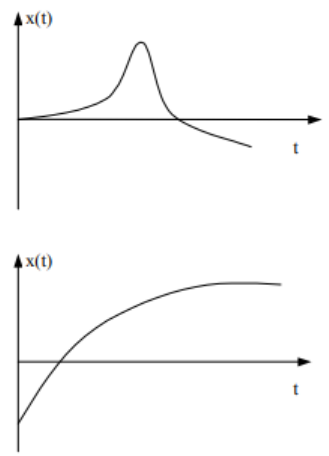

2)
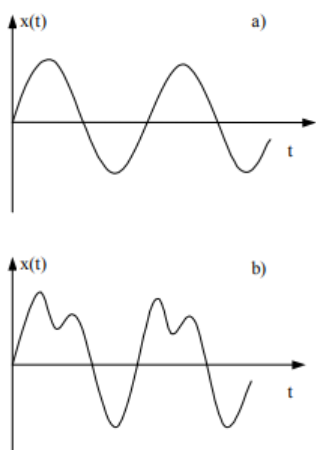

3)
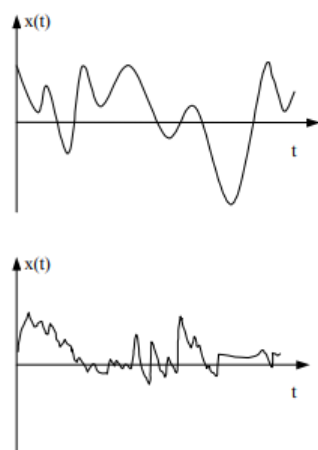

Fig. 7 Sample waveforms of signals: 1) non-periodic, 2) periodic: a) harmonic, b) polyharmonic, 3) random [17]. 


\section{Summary}

The constant development of industry and technology allows us to constantly improve the monitoring and diagnostic techniques that are already known to us. At the same time, we increasingly look at the future of technology through the prism of artificial intelligence or machine learning and the possibility of their application on an industrial scale. Undoubtedly, diagnostics and monitoring of managed systems is important for the operation of many industrial activities, and thanks to the diagnostic methods available, practiced and improved over the years, we are able to prevent serious failures and production downtime generating huge costs. The above article presents the most common faults in the discussed technology and a short cross-section of the possibilities of analysing diagnostic signals.

\section{References}

1. D. Mba, R.H. Bannister, G.A. Findlay, Proc. Instn. Mech. Engrs. vol. 13 part E, 153-170 (1999)

2. W. Gwiżdż, D. Lisowski, Silesian Electrical Journal, vol. 1'2016 (124), 11-16 (2016)

3. Z. Stambolinska, E. Rusiński, P. Moczko, Proactive Condition Monitoring of Low-Speed Machines (2015)

4. C. Cempel, F. Tomaszewski, Diagnostyka maszyn. Zasady ogólne. Przykłady Zastosowań, Międzyresortowe Centrum Naukowe Eksploatacji Majątku Trwałego (1992)

5. E. Golonka, M. Pająk, D. Kolar, MATEC Web Conf., vol. 332, art. number 01011 (2021)

6. C. Cempel, Diagnostyka wibroakustyczna maszyn, PWN (1989)

7. C. Cempel, Podstawy wibroakustycznej diagnostyki maszyn, WNT (1982)

8. T. Glinka, S. Szymaniec, Eksploatacja $i$ diagnostyka maszyn elektrycznych $i$ transformatorów, WNT (2019)

9. W. Cholewa, Dynamika $i$ diagnostyka maszyn wirnikowych - lata badań $i$ doświadczeń, Jubileusz 70-lecia urodzin oraz 45-lecia pracy naukowej prof. dra hab. inż. Jana Kicińskiego. Instytut Maszyn Przepływowych im. R. Szewalskiego Polskiej Akademii Nauk. Gdańsk, s. 61 -78, PAN (2018)

10. R. Walker, S. Perinpanayagam, I.K. Jennions, International Journal of Rotating Machinery, vol. 2013, article ID 856865 (2013)

11. R. Nowicki, Energetyka, vol. luty 2020, 70-76 (2020)

12. S. Szymaniec, Badania i eksploatacja $i$ diagnostyka zespołów maszynowych $z$ silnikami indukcyjnymi klatkowymi, Studia i monografie, vol. 333, Oficyna Wydawnicza Politechniki Opolskiej (2013)

13. FLUKE, 13 częstych przyczyn usterek silnika, Silniki, napędy, pompy, sprężarki, 21-6-2021 (2021)

14. S. Szymaniec, Diagnostyka stanu izolacji uzwojeń $i$ stanu tożyska silników indukcyjnych klatkowych $w$ warunkach przemystowej eksploatacji, Studia i Monografie, vol. 193, Oficyna Wydawnicza Politechniki Opolskiej (2016)

15. ISO 15243 Rolling bearings - Damage and failures - Terms, characteristics and causes

16. J. Szabatin, Podstawy teorii sygnałów, WKŁ (2007)

17. https://tiny.pl/9w8b3 